\begin{tabular}{|c|c|c|}
\hline & Revista de Ciências Agrārias & 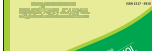 \\
\hline UNIVERSIDADE FEDERAL RURAL DA AMAZÔNIA & www.ajaes.ufra.edu.br & úle \\
\hline
\end{tabular}

AUTORES:

Rinaldo Batista Viana ${ }^{1}$

Elyzabeth da Cruz Cardoso $^{2}$

Irani Martins de Gouveia ${ }^{3}$

Marcus Luciano

Guimarães Rezende ${ }^{4}$

Bruno Moura Monteiro ${ }^{5}$

Cláudio Vieira de Araújo ${ }^{6}$

${ }^{1}$ Instituto de Saúde e Produção Animal, Universidade Federal Rural da Amazônia, 66077530, Belém PA, Brasil.

${ }^{2}$ Centro de Ciências Médicas, Universidade Federal Fluminense, 24320-340, Niteroi - RJ, Brasil.

${ }^{3}$ Universidade Federal Rural da Amazônia, 66.077-530, Belém PA, Brasil.

${ }^{4}$ Escola de Veterinária, Universidade Federal de Goiás, 74001-97, Goiânia GO, Brasil.

${ }^{5}$ Faculdade de Medicina Veterinária e Zootecnia, Universidade de São Paulo. 05508 270, São Paulo - SP, Brasil.

${ }^{6}$ Universidade Federal de Mato Grosso, 78550-000, Sinop - MT, Brasil.

Recebido: 15/06/2009

Aprovado: 18/10/2010

AUTOR CORRESPONDENTE:

Rinaldo Batista Viana

Email: rinaldo.viana@ufra.edu.br

PALAVRAS-CHAVE:

Mamite;

CCS;

Búfalas.

KEY WORDS:

Mastitis;

SCC;

Buffaloes.

\section{Avaliação da eficiência do Somaticell@ para o diagnóstico da contagem indireta de células somáticas no leite de búfalas}

\author{
Evaluation of the efficiency of the Somaticell ${ }^{\circledR}$ \\ diagnosis of an indirect somatic cell-count in \\ buffalo milk
}

Resumo: Objetivando avaliar o Somaticell ${ }^{\circledast}$ para o diagnóstico da contagem indireta de células somáticas no leite de búfalas foram conduzidos dois experimentos. No experimento A foram utilizadas seis búfalas, da raça Murrah, em diferentes fases da lactação, nas quais foram realizados os teste Somaticel1 ${ }^{\circledR}$, CMT e Alizarol. No experimento B foram utilizadas 49 búfalas, da raça Murrah, em diferentes fases de lactação, totalizando 196 amostras, nas quais foram realizados os testes Somaticell ${ }^{\circledR}$ e CCS em contador eletrônico. Observou-se que a contagem de células somáticas, feita através do Somaticell ${ }^{\circledR}$ mostrou valores significativamente maiores do que a contagem realizada em contador eletrônico. Estes valores obtidos no teste Somaticell ${ }^{\circledast}$ foram 4,7 vezes maiores do que aqueles obtidos para as mesmas amostras pela contagem de células somáticas em contador eletrônico. Na comparação entre Somaticell ${ }^{\circledR}$ e CCS em contador eletrônico para cada glândula mamária separadamente, ficou demonstrada uma disparidade entre os valores médios obtidos para ambas as técnicas, tendo sido os valores mínimos obtidos no Somaticell ${ }^{\circledR} 69$ vezes maiores do que aqueles obtidos pela CCS. As correlações entre ambos os testes foram baixas e insignificantes, demonstrando que ambas as técnicas comportamse distintamente na contagem de células somáticas no leite de búfalas.

Abstract: Two experiments were conducted with a view to evaluating the Somaticell ${ }^{\circledR}$ diagnosis involving an indirect somatic cell-count in buffalo milk. In experiment A, six Murrah buffaloes in different lactation phases were subjected to Somaticell®, CMT and Alizarol tests. In experiment B, 49 Murrah buffaloes in different lactation phases were used, giving a total of 196 samples, on which Somaticell@ and CCS tests were carried out using an electronic counter. It was observed that the counting of somatic cells performed using Somaticell@ provided values significantly higher than those obtained when using an electronic counter. The values obtained using the Somaticell@ test were 4.7 times higher than those obtained for the same samples by way of electronic counting of somatic cells. Comparison of Somaticell ${ }^{\circledR}$ and CCS electronic counting for each mammary gland separately revealed a disparity between the mean values obtained using both techniques, with the lowest values obtained using Somaticell@ 69 times higher than those obtained using CCS. The correlations between both tests were low and insignificant, demonstrating that the techniques behave differently when counting the somatic cells in buffalo milk. 


\section{Introdução}

Nos rebanhos leiteiros de todo o mundo, a doença que mais acomete as fêmeas bovinas e bubalinas no período puerperal é a mamite, processo inflamatório de origem infecciosa ou não, que atinge a mucosa, tecido secretor e/ou intersticial da glândula mamária (BIRGEL; BENESI, 1982).

A mamite determina perdas econômicas para os produtores, por aumentar os custos de produção e diminuir a produtividade (COSTA et al., 1999). $\mathrm{Na}$ Índia, as perdas determinadas pela mamite assintomática alcançam 35\% (VIANNI; LÁZARO, 2003), sendo a prevalência de mamite clínica em búfalas estimada em 12,2\% no estado indiano de Gujarat. As perdas ocasionadas pela mamite por búfala/lactação na Índia foram cerca de US\$ 8,80, sem incluir os custos relacionados ao tratamento, sendo os prejuízos anuais totais pela mamite em búfalas, no país, estimados em US\$ 526 milhões (VARSHNEY; NARESH, 2004).

No Paquistão, a doença foi reportada com uma prevalência de 20,6\%, enquanto no Iraque um estudo envolvendo 151 búfalas comprovou 31,9\% de casos positivos; no Egito, esta prevalência foi de $54,0 \%$ para as búfalas examinadas. No Brasil, a falta de informações ainda não permite estimar a prevalência da doença em todas as regióes do país (VIANNI; LÁZARO, 2003), porém Kapronezai (2004), citou uma prevalência de $8,81 \%$ para a mamite em búfalas criadas no Estado de São Paulo.

O principal fator que influencia o aumento das células somáticas no leite é o estado infeccioso, porém fatores como estádio de lactação, idade do animal, estação do ano e estresse podem influenciar a contagem de células somáticas (CCS), não sendo relevante se não ocorrer infecção da glândula mamária (HARMON, 1994; BEER, 1999; TONHATI et al., 2001).

Segundo Bastos (2004), os valores de células somáticas considerados como padrão de referência para o leite de búfalas, de acordo com o período de lactação (inicial, intermediário e final) são de 29.000; 29.000 e 26.000 células $\mathrm{mL}^{-1}$, respectivamente. Para Bastos (2004), o tipo de ordenha influenciou no número de células somáticas, sendo estabelecidos os valores de 22.000 células $\mathrm{mL}^{-1}$ para búfalas submetidas à ordenha manual e 32.000 células $\mathrm{mL}^{-1}$ para ordenha mecânica.

Ao estudarem a magnitude dos elementos constituintes do leite de búfalas de diversas raças, no Sri Lanka, Silva e Silva (1994) observaram que o núme- ro de células somáticas variou entre 50.000 e 375.000 células $\mathrm{mL}^{-1}$, com média de 140.000 células $\mathrm{mL}^{-1}$.

Apesar de não haver consenso, várias pesquisas e programas utilizaram a contagem de células somáticas na seleção de animais que seriam mais resistentes à mamite (SHOOT; SCHUTZ, 1994). Para assegurar a qualidade dos produtos derivados do leite de búfalas, na Europa foi estipulado o limite máximo de 400.000 células $\mathrm{mL}^{-1}$ para o leite in natura recém produzido.

Como a determinação das células somáticas é uma técnica preventiva, no sentido de minimizar a incidência de mamite nos rebanhos leiteiros, os métodos de diagnóstico da mamite assintomática incluem, além de exames microbiológicos e métodos químicos indiretos, a contagem de células somáticas (CCS) do leite dos quartos mamários individuais dos animais ou de amostras compostas do rebanho.

Dentre os vários tipos de testes utilizados no diagnóstico da mamite, pode-se citar o California Mastitis Test (CMT), a contagem de células somáticas (direta e indireta) e o teste do Alizarol. Outros testes, visando uma melhor avaliação em campo da contagem indireta de células somáticas têm sido desenvolvidos para auxiliar no diagnóstico e prevenção da mamite, podendo se destacar, entre esses, o Somaticel1 ${ }^{\circledR}$.

O Somaticell ${ }^{\circledR}$ é um indicador indireto de contagem de células somáticas desenvolvido para análise de leite bovino, que consiste em avaliar a viscosidade do leite. Quando as células somáticas entram em contato com o reagente do teste, a viscosidade do leite aumenta em uma proporção direta, ou seja, quanto maior a quantidade de células somáticas, maior a viscosidade do leite. É um teste utilizado tanto para identificação de um animal com infecção da glândula mamária (quando se analisa uma amostra de leite produzido por um animal específico) quanto na avaliação da qualidade do leite do rebanho (quando se analisa uma amostra de leite de diversos animais).

A prova do Alizarol é uma maneira rotineira e rápida de avaliar a acidez do leite, uma vez que ela é um parâmetro químico muito importante para a avaliação de sua qualidade para o processamento tecnológico (REIS et al., 2004). Para Brito et al. (2007), a estabilidade ao Alizarol é uma prova rápida, muito empregada nas plataformas de recepção como um indicador de acidez e estabilidade térmica do leite. De acordo com Vieira et al. (2005), essa análise não mede exatamente a acidez do leite, mas, 
sim, verifica sua tendência a coagular. O leite que coagula nessa prova não resiste ao calor, portanto, não pode ser misturado aos demais.

Para a acidez, os valores encontrados em bubalinos são mais elevados que os encontrados no leite de bovinos, devido à caseína, que, por conter dezenas de aminoácidos com características anfotéricas, age como ácido na titulação (REIS et al., 2004). A maioria dos autores encontra valores de acidez superiores a $18{ }^{\circ} \mathrm{D}$, portanto, acima dos padrões regulamentados para o leite de vaca. Somente em 1994 foi publicado, no Diário Oficial da União, o valor para acidez titulável no leite de búfalas, compreendido valores entre 14 e $23^{\circ} \mathrm{D}$ (TONHATI et al., 2004).

Acredita-se, portanto, que o diagnóstico eficaz e preciso é de extrema importância para controle da mamite, em búfalas. Para isso, há necessidade de exames físicos bem conduzidos e da utilização adequada dos exames auxiliares e ou complementares eficientes.

Deste modo, objetivou-se, nessa pesquisa, verificar a eficiência do teste do Somaticell ${ }^{\circledR}$ na contagem indireta de células somáticas (CCS) no leite de búfalas obtido por ordenha mecânica e manual.

\section{Material e Métodos}

Para se atingir os objetivos propostos foram conduzidos dois experimentos (A e B). No experimento A (controle da mamite em sistema mecanizado de ordenha) acompanhou-se a lactação de seis búfalas mantidas na Unidade de Bubalinocultura Leiteira Eva Daher Abufaiad do Instituto da Saúde e Produção Animal/Universidade Federal Rural da Amazônia, durante 210 dias de lactação. Nessa unidade as búfalas foram criadas em áreas de várzea e ordenhadas uma vez ao dia, em um sistema mecanizado de ordenha.

No experimento B (controle da mamite em ordenha manual), amostras de leite foram colhidas de 49 búfalas criadas em áreas de terra firme em uma fazenda situada às margens da BR 222, localizada no município de Rondon, Estado do Pará, onde se utiliza a ordenha manual, uma vez ao dia.

No experimento A foram realizados três tipos de teste: o CMT, o Somaticell ${ }^{\circledR 7}$ - contagem indireta de células somáticas e o teste do Alizarol.

Antes de cada ordenha, após a contenção dos animais, os quartos mamários foram lavados com água limpa e secos com papel-toalha. Foram desprezados os três primeiros jatos de leite e, em seguida, realizado o teste da Caneca de Fundo Escuro e ou caneca telada, para detectar possíveis grumos, raios de sangue ou mudanças na coloração do leite, características de uma possível mamite clínica. Em seguida, foi realizado o "pré-dipping", ou seja, a antissepsia de cada quarto mamário com solução à base de Dicloroisocianurato de sódio anidro ${ }^{8}$, diluído conforme recomendações do fabricante. Após a antissepsia, os tetos foram secos novamente com papeltoalha e, em seguida, foi realizada a ordenha mecânica. Após a ordenha foi realizado o "pós-dipping", com iodo glicerinado $10 \%$, que proporciona o fechamento dos canais galactófaros, evitando possíveis infecções.

No controle da mamite em sistema mecanizado de ordenha (experimento A) o CMT foi realizado a cada 14 dias. A interpretação da prova de Schalm e Noorlander (CMT) baseou-se na classificação sugerida por Birgel e Benesi (1982).

A cada 28 dias foi utilizado o kit Somaticell ${ }^{\circledR}$ para contagem indireta da quantidade de células somáticas no leite. Para este teste, após a ordenha individual dos animais, coletou-se uma amostra representativa de todo o úbere de cada animal, em um recipiente limpo e seco, identificando-o com o nome de cada animal. Em seguida, homogeneizou-se o leite de cada recipiente e retirou-se a amostra a ser avaliada. Colocou-se $2 \mathrm{~mL}$ de reagente no tubo e, em seguida, $2 \mathrm{~mL}$ de leite com a pipeta, homogeneizando a mistura por 30 vezes durante, no máximo, 20 segundos. Fechou-se o tubo, para invertê-lo logo em seguida, deixando o líquido escoar por 30 segundos, retornando-o, em seguida, à sua posição normal, esperando 5 segundos para realizar a leitura. A leitura foi efetuada com a utilização de um gabarito contendo faixas que indicam o número de células somáticas conforme o National Mastitis Council, USA (NMC).

O teste do Alizarol foi realizado a cada 28 dias juntamente com o Somaticell ${ }^{\circledR}$, durante o controle leiteiro, e teve como função verificar o grau de acidez e a estabilidade do leite ao tratamento térmico. O resultado foi obtido através da análise das cores possíveis no teste, segundo Reis et al. (2004).

No experimento B, assim como no experimento $A$, antes da colheita de cada amostra realizaram-se

\footnotetext{
${ }^{7}$ Intervet Schering-Plough.

${ }^{8}$ AGRISEPT® MC TABS - Intervet-Schering-Plough.
} 
os testes da caneca de fundo escuro e medidas higiênicas e antissépticas para a ideal obtenção das amostras. Para esse experimento foram realizados três tipos de teste, sendo o CMT e o Somaticell ${ }^{\circledast}$ empregados conforme descritos anteriormente, no Experimento A e a CCS determinada em contador automático. Foram colhidas amostras de leite de cada quarto mamário de cada búfala (196 amostras), as quais se encontravam em várias fases da lactação, sendo realizada somente uma colheita para tal experimento.

As amostras colhidas para a contagem de células somáticas em contador automático foram acondicionadas em recipientes de $50 \mathrm{~mL}$ cada, contendo pastilha de conservante Bronopol, identificadas, armazenadas em caixas específicas e enviadas para a Clínica do Leite, Departamento de Zootecnia, Escola Superior de Agricultura Luiz de Queiroz da Universidade de São Paulo (ESALQ/USP), onde foi realizada a contagem das células em contador automático, utilizando-se citometria de fluxo, através do equipamento Somatcount.

Foram comparados os valores da contagem de células somáticas avaliadas em contador automático e o valor obtido na escala do kit Somaticell ${ }^{\circledR}$ para a validação deste método para diagnóstico do teor de células somáticas no leite de búfalas.

Para efeito estatístico, os dados obtidos no experimento A foram tabulados e analisados através do delineamento inteiramente casualizado cujo tratamento foi dado pelo efeito da época de colheita da amostra ao longo da lactação, considerando os períodos de 0 a 30; 30 a 60; 60 a 90; 90 a 120; 120 a 150; 150 a 180 e 180 a 210 dias de lactação para as análises dos testes Somaticell ${ }^{\oplus}$ e Alizarol.

Os dados obtidos no experimento B foram tabulados e analisados através do Coeficiente de Correlação de Pearson, sendo os resultados da contagem de células somáticas em contador automático e do Somaticell ${ }^{\circledast}$ obtidos de acordo com o coeficiente de correlação e grau de significância, não considerando a fase de lactação. Para todas as análises foi utilizado o programa Statistical Analysis System (SAS, 2000).

\section{Resultados e Discussão}

Os resultados foram apresentados de acordo com cada experimento realizado, visto que as condições de criação (várzea x terra firme), bem como o tipo de ordenha (mecanizada $\mathrm{x}$ manual) dos animais foram diferentes.
Das seis fêmeas estudadas, todas apresentaram resultados negativos ao CMT, durante toda a lactação. Portanto, não se evidenciou a ocorrência de mamite nas búfalas ordenhadas mecanicamente. Tampouco foram observados os $8,81 \%$ de prevalência de mamite descritos por Kapronezai (2004) em um estudo realizado em São Paulo.

Na Tabela 1 são apresentados os dados referentes à média, desvio padrão, valores mínimos e máximos dos resultados obtidos para o Somatice $1^{\circledR}$, de acordo com o período da lactação. Foi possível observar que os maiores valores concentraram-se nos períodos de $180(175.800+145.677)$ e 210 (247.750 + 224.656) dias de lactação. Altos valores de células somáticas neste período, segundo Harmon (1994), Beer (1999) e Tonhati (2001) podem ser justificados pelo fato dos animais se encontrarem no período final de lactação, não sendo relevante a elevada CCS se não ocorrer infecção da glândula mamária. Segundo esses autores, outros fatores, como idade do animal, estação do ano e estresse, podem influenciar a CCS, não significando, necessariamente, uma infecção da glândula mamária.

Tabela 1 - Médias, desvios padrão, valores mínimos e máximos dos resultados obtidos no teste Somaticell ${ }^{\circledR}$ das búfalas estudadas, de acordo com o período de lactação. Estado do Pará, 2009.

\begin{tabular}{ccccc}
\hline Período de lactação & $\mathbf{n}$ & Média \pm Desvio Padrão & Mínimo & Máximo \\
\hline $0-30$ & 3 & $79.000 \pm 00000$ & 79.000 & 79.000 \\
$30-60$ & 5 & $119.600 \pm 91.059$ & 69.000 & 282.000 \\
$60-90$ & 5 & $114.000 \pm 73.144$ & 69.000 & 244.000 \\
$90-120$ & 6 & $133.833 \pm 109.864$ & 79.000 & 379.000 \\
$120-150$ & 6 & $116.167 \pm 32.682$ & 79.000 & 166.000 \\
$150-180$ & 5 & $175.800 \pm 145.677$ & 69.000 & 418.000 \\
$180-210$ & 4 & $247.750 \pm 224.656$ & 79.000 & 560.000 \\
\hline Média Geral: $140.879 ; n=$ número de animais.
\end{tabular}

Kapronezai (2004) também afirmou que a quantidade e os tipos de células presentes no leite variam sob condições fisiológicas e patológicas. Fonseca e Santos (2000) citam que fatores como o estresse calórico durante o verão fazem com que os animais apresentem menor consumo de alimentos e, consequentemente, menor produção de leite, o que leva a uma maior concentração das células somáticas.

Na Figura 1 são apresentados os dados com a variação da contagem indireta de células somáticas $\left(\right.$ Somatice $11^{\circledR}$ ) dos animais, durante um período de lactação de 30 a 210 dias de duração, sendo enfatizado que o final da lactação foi o período em que a média dos valores de células somáticas foi considerada elevada, constatação descrita por Harmon (1994) e Beer (1999). 


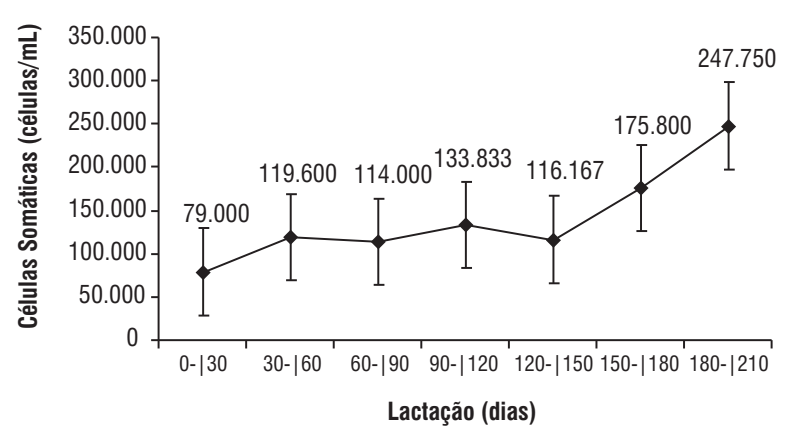

Figura 1 - Contagem indireta de células somáticas das búfalas estudadas, de acordo com o período pós-parto, obtida no teste Somaticell ${ }^{\circledR}$. Estado do Pará, 2009.

Os valores médios obtidos no Somaticell ${ }^{\circledR}$ foram de 140.879 células $\mathrm{mL}^{-1}$. Estes valores são similares àqueles mencionados por Silva e Silva (1994) e consideravelmente maiores do que aqueles descritos por Bastos (2004).

Na Tabela 2 são expostos os dados com variação de cor do teste do Alizarol. Foi possível observar que, durante todo o período de lactação, a coloração predominante foi o castanho tijolo, demonstrando que o $\mathrm{pH}$ do leite encontrava-se dentro dos valores aceitáveis de acidez, conforme descritos por Reis et al. (2004) e Brito et al. (2007).

Tabela 2 - Frequência dos resultados obtidos do teste do Alizarol nas búfalas estudadas, de acordo com o período pós-parto. Estado do Pará, 2009.

\begin{tabular}{ccccc}
\hline $\begin{array}{c}\text { Período de } \\
\text { lactaçãa }\end{array}$ & $\mathbf{n}$ & $\begin{array}{c}\text { Teste do alizarol } \\
\text { Castanho Tijolo } \\
(\%)\end{array}$ & $\begin{array}{c}\text { (coloração obtida) } \\
\text { Castanho Claro } \\
(\%)\end{array}$ & $\begin{array}{c}\text { Amarela } \\
(\%)\end{array}$ \\
\hline $0-\mid 30$ & 3 & $2(66,6)$ & $1(33,3)$ & 0,0 \\
$30-\mid 60$ & 5 & $4(80,0)$ & $1(20,0)$ & 0,0 \\
$60-\mid 90$ & 5 & $5(100,0)$ & $0(0,0)$ & 0,0 \\
$90-\mid 120$ & 6 & $5(83,3)$ & $1(6,7)$ & 0,0 \\
$120-\mid 150$ & 6 & $5(83,3)$ & $1(16,7)$ & 0,0 \\
$150-\mid 180$ & 5 & $4(80,0)$ & $1(20,0)$ & 0,0 \\
$180-\mid 210$ & 4 & $3(75,0)$ & $1(25,0)$ & 0,0 \\
\hline Coloração Castanho Tijolo: 14 a 18 oD; Coloração Castanho Claro: 19 a 20 oD; Coloração Amarela: \\
acima de 210D; $n=$ número de animais.
\end{tabular}

Na Tabela 3 são expostos os dados referentes à análise comparativa do teste do Alizarol e teste Somaticell $^{\circledast}$. Foram estabelecidos três níveis de risco relacionados ao teste de Somaticell ${ }^{\circledR}$, tomando-se como base o gabarito de interpretação do resultado da leitura do mesmo, recomendado pelo fabricante: risco 1: a probabilidade de que o úbere do animal não esteja infectado é extremamente elevada; risco 2: a probabilidade de que o úbere do animal esteja infectado é baixa; risco 3: a probabilidade de que o úbere do animal esteja infectado é bastante elevada.
Tabela 3 - Frequência de resultados obtidos através da correlação entre teste do Alizarol e Somaticell@ nas búfalas estudadas, de acordo com o período de lactação. Estado do Pará, 2009

\begin{tabular}{ccccc}
\hline \multirow{2}{*}{ Alizarol } & \multicolumn{4}{c}{ Somaticell } \\
& Risco 1 & Risco 2 & Risco 3 & Total \\
\hline CC & $7(17,07 \%)$ & $2(4,88 \%)$ & $0(0 \%)$ & $9(21,95 \%)$ \\
CT & $21(51,22 \%)$ & $6(14,63 \%)$ & $5(12,2 \%)$ & $32(70,05 \%)$ \\
Total & $28(68,14 \%)$ & $8(19,51 \%)$ & $5(12,2 \%)$ & $41(100 \%)$ \\
\hline
\end{tabular}

CC: Castanho Claro; CT: Castanho Tijolo.

O teste do Alizarol demonstrou que 70,05\% do total de amostras avaliadas obteve coloração Castanho Tijolo, coloração que classifica o leite como dentro do padrão normal de acidez, citado por Reis et al. (2004) e Brito et al. (2007). Esses resultados comprovam a eficiência do Programa de Higiene adotado na ordenha, mesmo se tratando de período chuvoso (dezembro de 2005 a fevereiro de 2006), que Pianta (1997) considera como fator ambiental predisponente ao aparecimento da mamite. Isso provavelmente se justifica pelo eficiente antisséptico utilizado no "pré-dipping" (AGRISEPT ${ }^{\circledR}$ MC TABS) e pelas boas e adequadas práticas de higiene e manejo adotadas na ordenha.

Como os testes do CMT e do Alizarol mostraram-se negativos para o diagnóstico de mamite assintomática, os animais que apresentaram valores considerados elevados de células somáticas no Somaticell ${ }^{\circledR}$, durante a lactação, não foram considerados positivos para a infecção da glândula mamária.

Na Tabela 4 são expostos os dados referentes à média, desvios padrão, valores mínimos e máximos dos resultados obtidos na CCS e no Somaticell ${ }^{\circledR}$ das búfalas ordenhadas manualmente.

Tabela 4 - Médias, desvios padrão, valores mínimos e máximos dos resultados obtidos nos testes Somaticell ${ }^{\circledR}$ e CCS*. Estado do Pará, 2009.

\begin{tabular}{ccccc}
\hline Variável & Média & Desvio padrão & Valor mínimo & Valor máximo \\
\hline CCS $^{*}$ & 26.924 & 56.785 & 1.000 & 387.000 \\
Somaticell $^{\circledast}$ & 126.400 & 93.108 & 69.000 & 470.000 \\
\hline *
\end{tabular}

A média dos valores da CCS encontrada foi 26.924 células $\mathrm{mL}^{-1}$. Esses valores são similares àqueles descritos por Bastos (2004), ao estudar 98 búfalas adultas e lactantes, da raça Murrah, criadas em São Paulo, estabelecendo como padrão de referência para o leite, de acordo com o período de lactação (inicial, intermediário e final), os valores de contagem de células somáticas iguais a 29.000, 29.000 e 26.000 células $\mathrm{mL}^{-1}$, respectivamente, e de acordo com o tipo de ordenha de 22.000 células $\mathrm{mL}^{-1}$, 
para ordenha manual, e 32.000 células $\mathrm{mL}^{-1}$, para ordenha mecânica.

Todavia, os valores aqui obtidos para CCS vão de encontro aos valores médios estabelecidos por Silva e Silva (1994), os quais mencionaram que a contagem de células somáticas no leite normal de búfalas variou entre 50.000 e 375.000 células $\mathrm{mL}^{-1}$, com média de 140.000 células $\mathrm{mL}^{-1}$. Estes maiores valores encontrados por Silva e Silva (1994), provavelmente podem ter ocorrido devido aos diferentes manejos adotados nas propriedades, período de lactação, tipo de ordenha (manual ou mecânica), frequência diária de ordenha, bem como as práticas de higiene utilizadas antes, durante e pós-ordenha.

Muito embora Bastos (2004) tenha observado que o tipo de ordenha influenciou a CCS, observando maiores valores de CCS no leite de búfalas ordenhadas mecanicamente, diferentemente, nesse estudo, os valores médios obtidos na CCS em contador automático, no leite de búfalas ordenhadas manualmente (26.924 células $\mathrm{mL}^{-1}$ ) foram comparativamente maiores do que aqueles obtidos pelo Somaticell $^{\circledast}$, no leite das búfalas ordenhadas mecanicamente (140.879 células $\mathrm{mL}^{-1}$ ).

Evidencia-se, na tabela 4 , que os valores obtidos pelo teste Somaticel1 ${ }^{\circledR}$, no presente estudo, são 4,7 vezes maiores do que aqueles obtidos para as mesmas amostras pela contagem de células somáticas em contador eletrônico. O elevado valor máximo obtido no leite das búfalas ordenhadas manualmente através da CCS em contador automático pode ser justificado pelo fato desses animais se encontrarem no final da lactação, em que fisiologicamente há um aumento na CCS, conforme observaram Harmon (1994) e Beer (1999).

Na Tabela 5 os valores comparativos entre o Somaticell ${ }^{\circledR}$ e a CCS eletrônica para cada glândula isoladamente também demonstram uma disparidade entre os valores médios obtidos para ambas as técnicas, tendo sido os valores mínimos obtidos no Somaticell ${ }^{\circledR}$ 69 vezes maiores do que os obtidos pela CCS.

Tabela 5 - Médias, desvios padrão, valores mínimos e máximos dos resultados obtidos nos testes Somaticell@ e CCS*, por quarto mamário examinado. Estado do Pará, 2009.

\begin{tabular}{lcccccccc}
\hline \multirow{2}{*}{ Variáveis } & \multicolumn{4}{c}{ CCS* $^{*}$} & \multicolumn{5}{c}{ Somaticell $^{\circledR}$} \\
& TAD & TAE & TPD & TPE & TAD & TAE & TPD & TPE \\
\hline Média & 34.333 & 24.177 & 25.333 & 23.386 & 146.208 & 114.422 & 120.208 & 123.795 \\
$\begin{array}{l}\text { Desvio } \\
\text { padrão }\end{array}$ & 68.274 & 38.279 & 59.529 & 56.968 & 114.698 & 83.482 & 79.023 & 90.120 \\
$\begin{array}{l}\text { Valor } \\
\text { mínimo }\end{array}$ & 1.000 & 1.000 & 1.000 & 1.000 & 69.000 & 69.000 & 69.000 & 69.000 \\
$\begin{array}{l}\text { Valor } \\
\text { máximo }\end{array}$ & 286.000 & 151.000 & 387.000 & 334.000 & 470.000 & 418.000 & 418.000 & 379.000 \\
\hline *Contagem das células somáticas.
\end{tabular}

Esses distintos resultados na contagem de células somáticas obtidas em ambas as técnicas podem ser melhor visualizados nas correlações apresentadas na Tabela 6 , onde se observa que estas foram muito baixas, com coeficiente de correlação 0,18 e grau de significância igual a 0,0113 . Isso demonstra que as duas técnicas tiveram comportamento distinto para análise da quantidade de células somáticas no leite de búfalas. Vale ressaltar que o Somaticell ${ }^{\circledR}$ foi desenvolvido para as características organolépticas do leite de vacas, que possui valores de células somáticas bem maiores que o de búfalas.

Tabela 6 - Correlações obtidas entre as técnicas CCS* e Somaticell ${ }^{\circledast}$ para cada variável analisada. Estado do Pará, 2007.

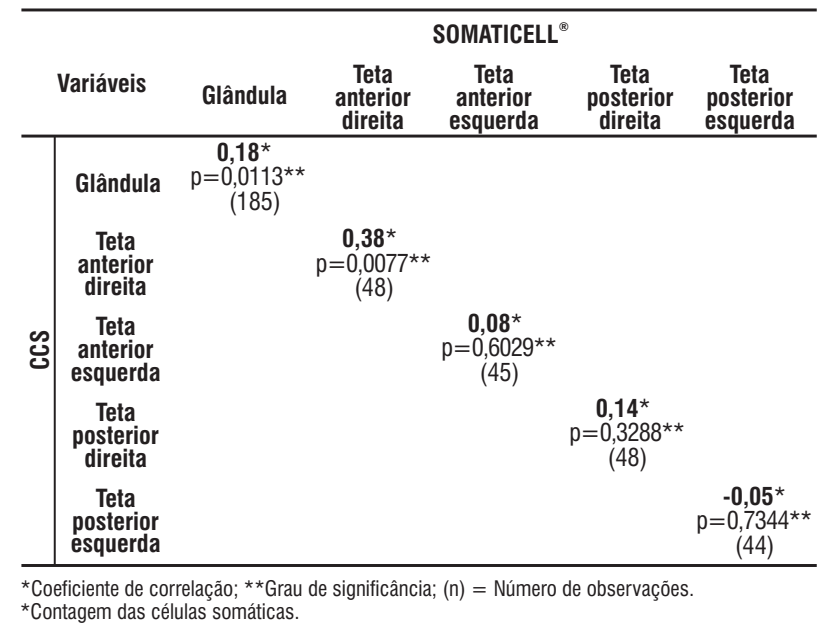

O número de células somáticas obtido neste estudo, nas amostras de leite de búfala colhidas em várias fases da lactação, foi evidentemente menor do que o mencionado por vários pesquisadores para o leite de bovinos (SCHULTZ, 1977; JONES, 1986). A existência dessas diferenças pode ser justificada por inúmeras condições, como particularidades da espécie, fatores de variabilidade inerentes ao sistema de criação e manejo de produção das búfalas leiteiras estudadas. Por isso, provavelmente, os maiores valores obtidos no Somaticell ${ }^{\circledR}$ para as búfalas decorreram do fato desse teste ter sido padronizado para as características organolépticas de bovinos e não de bubalinos.

\section{Conclusões}

Os resultados obtidos pelo teste Somaticell ${ }^{\circledR}$, no presente estudo, demonstraram que esse teste, na escala de CCS que apresenta em seu tubete, não é indicado para o diagnóstico de mamite assintomática nas búfalas estudadas. Acredita-se na necessi- 
dade de uma nova escala, com valores menores, adequados às características do leite de búfalas, para a condução de um novo trabalho de correlação com a contagem de células somáticas em contadores eletrônicos.

\section{Agradecimentos}

À Intervet Schering-Plough, à Fazenda Santa Fé e à Associação dos Criadores de Búfalos do Pará, pelo suporte financeiro dado a esta pesquisa.

\section{Referências}

BASTOS, P.A.S. Constituição físico-química, celular e microbiológica do leite de búfalas (Bubalus bubalis) criadas no Estado de São Paulo. Tese (Doutorado), São Paulo, 2004.

BEER, J. Doenças infecciosas em animais domésticos. São Paulo: Roca, 1999. p.3.

BIRGEL, E.H.; BENESI, F.J. Patologia clínica veterinária. São Paulo: FMVZ, 1982. p.185-195.

BRITO, M.A.; BRITO J.R.; ARCURI, E.; LANGE, C.; SILVA, M. ; SOUZA, G. Estabilidade ao Alizarol. Ministério da Agricultura, Pecuária e Abastecimento. Agência de Informação, Agronegócio do Leite. Disponível em: http://www.agencia.cnptia.embrapa.br/. Acesso em: 18/02/2007.

COSTA, E.O.; RIBEIRO, A.R.; WATANABE, E.T.; SILVA. J. A. B.; GARINO JUNIOR, F.; BENITES, N. R.; HORIUTI, A.M. Mastite subclínica : prejuízos causados e os custos de prevenção em propriedades leiteiras. Napgama, São Paulo, v.2, n.2, p.16-20, mar./ abr. 1999.

FONSECA, L.F.L. ; SANTOS, M.V. Qualidade do leite e controle de mastite. São Paulo: Lemos Editorial, 2000. p.175.

HARMON, R.J. Physiology of mastitis and factors affecting somatic cell counts. Journal of Dairy Research, p.2103-2112, 1994.

JONES, G.M. Reducing somatic cell count: meeting the 1986 challenge - impact on producer and processor. Journal of Dairy Science, v.69, n.4, p.16991717, 1986.

KAPRONEZAI, J. Estudo de provas microbioló-gicas e celulares em amostras de leite provenientes de fêmeas bubalinas (Bubalus bubalis) no Estado de São Pau- lo. Dissertação (Mestrado em Medicina Veterinária) Faculdade de Medicina Veterinária e Zootecnia, Universidade de São Paulo, 2004.

PIANTA, C. Mastite bovina: informações ao produtor. Porto Alegre: Fepagro, 1997. 12p. (Circular técni$\mathrm{co}, 15)$.

REIS, J.S.; MYYAGI, E.S.; CHANDELIER, R.A.; BERGAMASEO, A.F.; LOBATO, V.; MOURA, C.J. de. Disponível em: < http://www.editora.ufla.br/boletim > Acesso em: 28.11.2004.

SAS INSTITUTE. SAS. Cary, 2000. Software v.8.1.

SCHALM, O.W.; NOORLANDER, D.O. Experiments and observations to development of California Mastitis Test. Journal of the American Veterinary Medical Association, v.130, n.5, p.199-207, 1957.

SCHULTZ, L.H. Somatic cell counting of milk in production testing programs as a mastitis control technique. Journal of American Veterinary Medical Association, v.170, n.10, p.1244-1246, 1977.

SHOOT, G.E.; SCHUTZ, M.M. Selection on somatic cell score to improve resistence to mastitis in the United tatess. Journal of Dairy Science, v.77, n.2, p.648-658, 1994.

SILVA, I.D.; SILVA, K.F.S.T. Total and differential cell counts in buffalo (Bubalus bubalis) milk. Buffalo Journal, v.10, n.2, p.133-137, 1994.

TONHATI, H.; CERON-MUNOZ, M.; DUARTE, J. In: Simpósio Paulista de Bubalinocultura, 2. Pirassununga. Anais... Pirassununga, 2001.

TONHATI, H.; CANAES, T.S.; LIMA, A.L.F. Fatores que afetam a contagem de células somáticas e suas relações com a composição e produção de leite de búfalas. Disponível em: < http://www.spmv.org.br/ conpavet2004/palestras $>$. Acesso em: 17.05.2005.

VARSHNEY, J.P.; NARESH, R. Evaluation of a homeopathic complex in the clinical management of udder diseases of riverine buffaloes. Buffalo Udder Diseases and Homeopathy, India, v.93, p.17-20, 2004.

VIANNI, M.C.E.; LÁZARO, N.S. Perfil de susceptibilidade a antimicrobianos em amostras de cocos grampositivos, catalase negativos, isoladas de mastite subclínica bubalina. Pesquisa Veterinária Brasileira, Rio de Janeiro, v.23 n.2, p.47-51, abr./jun. 2003. Disponível em: http://www.scielo.br/scielo.

VIEIRA, L.C.; KANEYOSH, C.M.; FREITAS, H. Criação de gado leiteiro na Zona Bragantina. Embrapa Amazônia Oriental. Dez/2005. Disponível em: http:// sistemasdeproducao.cnptia.embrapa.br/FontesHTML/ Leite/GadoLeiteiroZonaBragantina/paginas/ qualidade.htm. Acesso em: 20/02/2007. 